\author{
РАЗВИТИЕ МЕЛКОЙ МОТОРИКИ У ДЕТЕЙ \\ С ОСОБЫМИ ОБРАЗОВАТЕЛЬНЫМИ ПОТРЕБНОСТЯМИ \\ (ИЗ ОПЫТА РАБОТЫ РЕСУРСНОГО ЦЕНТРА \\ ИНКЛЮЗИВНОГО ОБРАЗОВАНИЯ В РЕСПУБЛИКЕ МОЛДОВА) \\ РОЗВИТОК ДРІБНОЇ МОТОРИКИ У ДІТЕЙ З ОСОБЛИВИМИ \\ ОСВІТНІМИ ПОТРЕБАМИ (З ДОСВІДУ РОБОТИ РЕСУРСНОГО \\ ЦЕНТРУ ІНКЛЮЗИВНОЇ ОСВІТИ В РЕСПУБЛІЦІ МОЛДОВА)
}

\title{
THE DEVELOPMENT OF FINE MOTOR SKILLS OF SPECIAL NEEDS CHILDREN (BASED ON THE EXPERIENCE FROM THE INCLUSIVE EDUCATION RESOURCE CENTRE IN THE REPUBLIC OF MOLDOVA)
}

Статья посвящена одной из актуальных проблем - развития мелкой моторики y детей с особыми образовательными потребностями. В частности, приводятся примеры из опыта работы ресурсного центра инклюзивного образования в Республике Молдова.

В настоящее время число детей с особыми образовательными потребностями постоянно увеличивается. Проблема поиска новых эфрфективных направлений и способов оказания индивидуальной помощи этой категории детей становится всё более актуальной. Одна из челей эрготерапии состоит в развитии мелкой и крупной моторики. В данной статье описываются приёмы развития мелкой моторики у детей. Эти приёмы значительно улучшают активность в повседневной жизни и навыки самообслуживания, что способствует их социализации и интеграции в обществе. Основная задача coстоит в ознакомлении молодых педагогов и родителей с разновидностью упражнений, которые не только максимально восстановят двигательные функции, но и помогут стать самостоятельным, социально приспособленным и независимым в быту человеком. Успех приносит удовольствие, и работа педагога заключается в организации таких занятий, которые не только позволяли бы добиваться успеха, но и были бы весёлыми и интересными. Во время игровой деятельности ребёнок овладевает полезными навыками, которые потребуются ему во взрослой жизни. В процессе занятий используются игры и упражнения, направленные на развитие социальных навыков, на развитие сенсорного восприятия, памяти и внимания, арттерапия, мероприятия по личной гигиене. Позитивное отношение к работе и энтузиазм во время занятий - это те качества, которые необходимы для успешной работы с ребёнком.

Таким образом, главная цель занятий в школе - это социальная адаптация, которая требует комплексного и индивидуального подхода к ребёнку. В таких ситуациях имеет значение всё: окружение человека, образ его жизни, личные склонности и увлечения, уровень интеллекта. Всё это очень важно, поскольку задача педагога улучшить качество жизни и дать ребёнку возможность не только самостоятельно обслуживать себя, но и быть полезным обществу.

Ключевые слова: мелкая моторика, развитие, дети с особыми образовательными потребностями, ресурсный чентр, вспомогательный педагог.

Стаття присвячена одній з актуальних проблем - розвитку дрібної моторики у дітей з особливими освітніми потребами. Зокрема, наводяться приклади з досвіду роботи ресурсного чентру інклюзивної освіти в Республіці Молдова.

Натепер число дітей з особливими освіт німи потребами постійно збільшується. Проблема пошуку нових ефективних напрямів і способів надання індивідуальної допомоги иій категорії дітей стає все більш актуальною. Одна з цілей ерготерапії полягає в розвитку дрібної й великої моторики. У чій статті описуються прийоми розвитку дрібної моторики у дітей. Ці прийоми значно покращують активність у повсякденному житті та навички самообслуговування, що сприяє їх соціалізації і інтеграції в суспільстві. Основне завдання полягає в ознайомлення молодих педагогів і батьків 3 різновидом вправ, які не тільки максимально відновлять рухові функції, але і допоможуть стати самостійною, соиіально пристосованою і незалежною у побуті людиною. Успіх приносить задоволення, і робота педагога полягає в організації таких занять, які не тільки би давали змогу досягати успіху, але й були б веселими та чікавими. Під час ігрової діяльності дитина опановує корисні навички, що знадобляться їй у дорослому житті. У прочесі занять використовуються ігри та вправи, що спрямовані на розвиток соціальних навичок, на розвиток сенсорного сприйняття, пам'яті та уваги, арттерапія, заходи з особистої гігієни. Позитивне ставлення до роботи і ентузіазм під час занять - че ті якості, які необхідні для успішної роботи з дитиною.

Таким чином, головна мета занять у школі - це соціальна адаптація, яка вимагає комплексного та індивідуального під ходу до дитини. У таких ситуаціях має значення все: оточення людини, спосіб ї життя, особисті схильності та інтереси, рівень інтелекту. Усе це дуже важливо, 
оскільки завдання педагога - поліпшити якість життя дитини і дати їй можливість не тільки самостійно обслуговувати себе, але і бути корисним суспільству.

Ключові слова: дрібна моторика, розвиток діти з особливими освітніми потребами, ресурсний центр, допоміжний педагог.

This article focuses on one of the most urgent problems of the development of fine motor skills of special needs children. In particular, it is based on the experience from the inclusive education resource centre in the Republic of Moldova.

Nowadays, the number of special needs children is constantly increasing. Thus, the problem of finding new effective directions and ways to provide individual assistance to this category of children is up to date. One of the goals of the occupational therapy is to develop fine and large motor skills. This article illustrates techniques used for the development of children's fine motor skills. The presented techniques lead to the improvement of children's everyday life activity and their self-care skills that in consequence contribute to their socialization and social integration. The main task is to familiarize young teachers and parents with the variety of exercises that will restore special needs children's motor functions, and also help them becoming independent, socially fit and able to do everyday life activities independently. As success brings pleasure, the teacher's job is to organize classes that would not only make it possible to succeed, but would also be interesting and motivating for the child. The children develop better useful skills that will help them in their future real life during the educational game performance. Different types of games and exercises are used during the classes in order to develop children's social skills. Such activities as games for developing sensory perception, memory and attention, art-therapy, and games which reflect personal hygiene measures are also used. A positive attitude to work and enthusiasm during classes are those qualities that are necessary for a successful progress with a special needs child.

Thus, the main goal of the classes at school, as a consequence, is the social adaptation, which requires an integrated and individual approach to the child. In such situations, everything matters: the environment, educator's lifestyle, personal preferences and hobbies, and the level of intelligence. Everything mentioned above, is very important, since the task of the educator is to improve the quality of life and give these children the opportunity not only to take care of them independently, but also to be integrated and active within the society.

Key words: fine motor skills, development, special needed children, resource centre, support teacher.
Источник способностей и дарований детей на кончиках их пальцев.

\section{В. Сухомлинский}

Общество, в котором мы живём, стремится к равным возможностям для всех детей посещать одну и ту же школу и учиться вместе, независимо от их культурной, социальной, религиозной и экономической принадлежности или их интеллектуальных, или фризических способностей и потребностей. В настоящее время число детей с особыми образовательными потребностями постоянно увеличивается, а проблема поиска новых эфрфективных направлений, способов оказания индивидуальной психо-педагогической помощи этой категории детей становится всё более актуальной.

Bсе дети могут освоить жизненно важные навыки, но если большинство обычных детей учится в естественной среде, наблюдая за другими людьми и подражая им, то детям с особыми потребностями нужно больше времени, специальное обучение и индивидуальные условия.

В последнее десятилетие разработано большое количество методик для восстановительного лечения двигательных, речевых и психических функций детей. Кроме того, существуют методики эрготерапии, которые значительно улучшают у детей с ограниченными возможностями активность в повседневной жизни и навыки самообслуживания, что способствует их социализации и интеграции в общество здоровых людей (О. В. Камаева, 2003, Е. Townsend, 1997, М. Nestadi, 1998).

Родители детей с ограниченными возможностями активно изучают информацию об эрго- терапии, чтобы адаптировать обычную домашнюю среду в пространство для формирования и развития у ребёнка жизненно важных навыков. В эрготерапии термин «занятость» (occupation) относится не только к работе или трудотерапии. Термин «занятость», с точки зрения эрготерапии, характеризует различные виды деятельности, которые встречаются в жизни каждого человека и придают ей смысл.

Кара Косински, американский эрготерапевт и мама двоих сыновей с аутизмом, разработала системный подход, который успешно практикует в работе с детьми с расстройствами аутистического спектра. «Меня часто спрашивают, почему мои терапевтические сессии выглядят так, будто я всего лишь играю с ребёнком. Если речь идёт о детях, то именно в игровой деятельности и заключается их «работа». Дети учатся во время различных дел, которыми они занимаются в повседневной жизни. Когда ребёнок понимает, что его действия вызывают ответную реакцию (от другого человека или от игрушки), он переживает ощущение успеха. Если та или иная деятельность успешна, то ребёнок с большей долей вероятности захочет её повторить. И наоборот, если ребёнку не удалось достичь успеха, он, скорее всего, не захочет заниматься этим делом снова» [6, с. 9].

Одна из целей эрготерапии состоит в развитии мелкой и крупной моторики. В данной статье описаны в контексте вышеупомянутых заявлений приёмы развития мелкой моторики у детей с особыми образовательными потребностями, которые обеспечат исправление трудностей в обучении 
структурного, организационного, эмоционального или иного характера у детей.

Основная задача этой статьи состоит в ознакомление молодых родителей и вспомогательных педагогов с разновидностью упражнений, которые не только максимально восстановят двигательные функции ребёнка, но и помогут стать самостоятельным, социально приспособленным и независимым в быту, независимо от того, какие у него есть нарушения, ограничения жизнедеятельности или ограничения участия в жизни общества.

При помощи службы психо-педагогической поддержки и администрации лицея был создан и адаптирован фрункциональный ресурсный центр для инклюзивного образования, подходящий для свободного выбора, изучения и манипулирования игрушками, учебными материалами и спортивным инвентарём (мат, ковёр, закрытые шкафы, гимнастическая лестница), что облегчает двигательную деятельность учеников.
В ресурсном центре также можно использовать и школьные принадлежности, которые находятся под рукой: ручки, карандаши, клей, цветные карандаши, гуашь, кисточки, пластилин, тетради для прописи, альбомы, цветная бумага, таймер и песочные часы.

Успех приносит удовольствие, и работа педагога заключается в организации таких занятий, которые не только позволяли бы добиваться успеха, но и были бы весёлыми и интересными $[6$, c. 10]. Что касается работы, то игра - это и есть работа, которую выполняет ребёнок. Во время игровой деятельности он овладевает полезными навыками, которые потребуются ему во взрослой жизни. Таким образом, игра ребёнка в «магазин», в «дочки-матери» или использование игрушечных инструментов готовит его к соответствующим видам деятельности во взрослом возрасте [3, с. 25].

Коробки с кнопками и бусы разных цветов и размеров, разные макаронные изделия, мозаика,
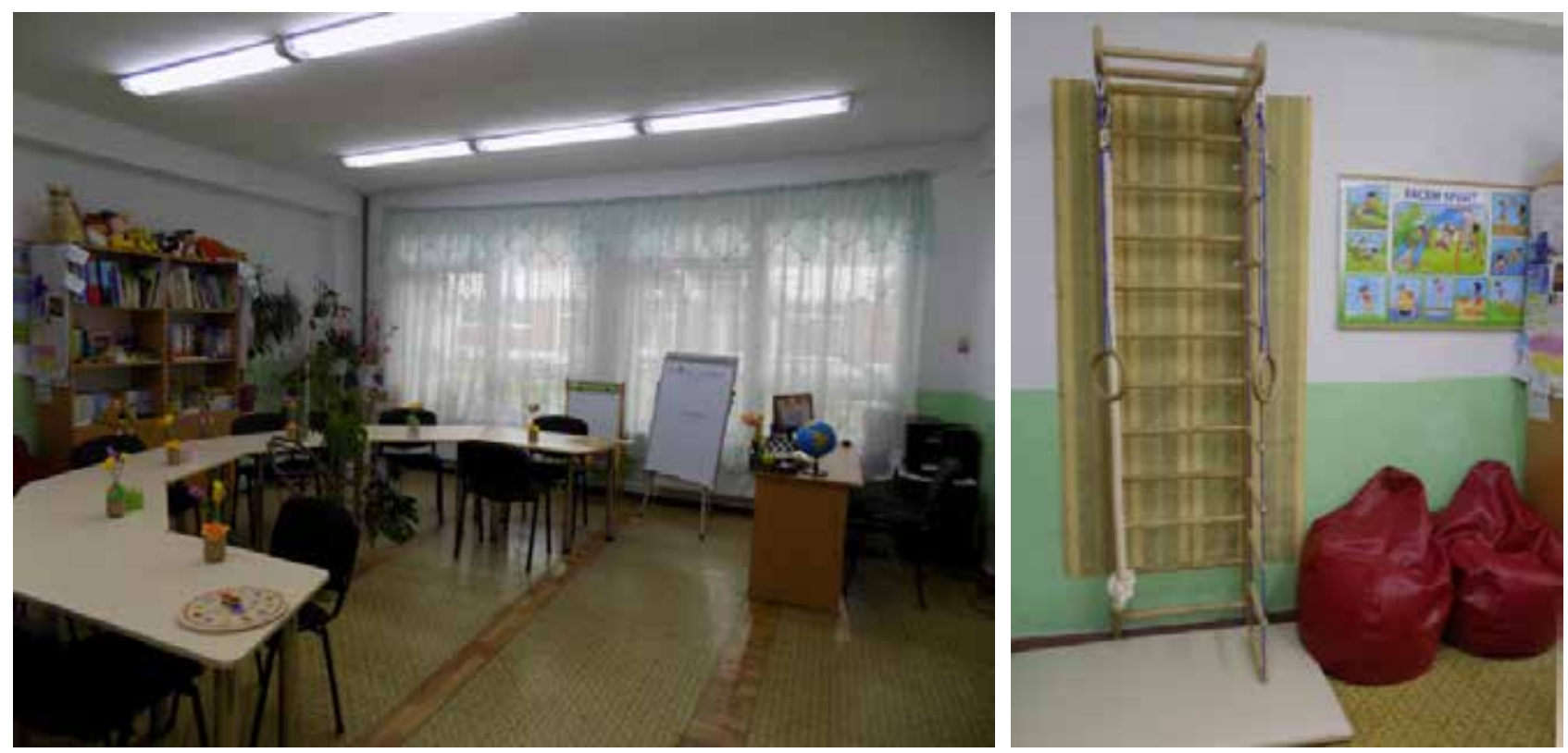

Рис. 1. Ресурсный центр для инклюзивного образования
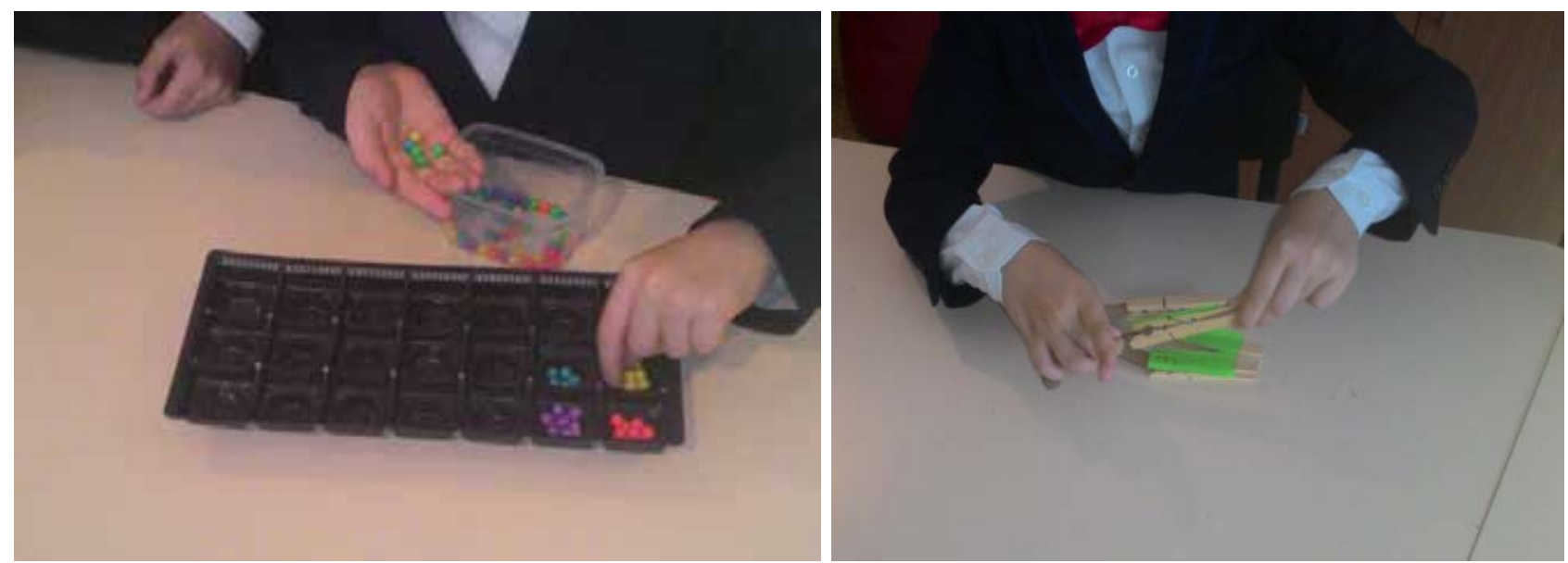

Рис. 2. Сортировочные упражнения 
карандаши, шарики, кубики, пенопласт, палочки, семена подсолнечника, пластилин доступны каждому для организации занятий с учениками в зависимости от их психомоторного и интеллектуального развития.

Перед началом занятий проводятся ряд упражнений по активации нервных окончаний при помощи мячей разных по размерам и текстуре (гладкие, шипованные и заполненные орбизом).

При активации нервных окончаний используется мелкая фрурнитура:

- шпажка;

- прищепка;

- ключ;

- лист бумаги;

- бисер;

- карандаш с рифлёной поверхностью;

и более крупные предметы:

- кубик с гранью 4 см;

- скалка;

- книга;

- сумка с ручкой;

- мячик диаметром 6 см.

Если нужен захват мелких предметов и их удержание, то предлагается дощечка с отверстиями, болты, шайбы и гайки.

В дальнейшем подбираются упражнения, которые развивают практическую направленность:

- переложить предмет;

- переставить стул;

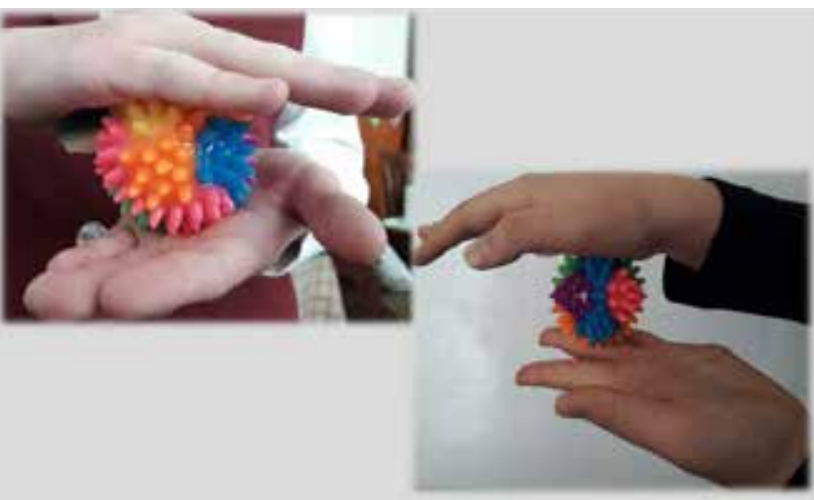

- набрать номер телефона;

- открыть крышку.

Также используются игры:

- шахматы;

- домино;

- шашки;

- лабиринты;

- лепка;

- конструктор;

- пазлы;

- рисование кисточкой, карандашами, фрломастерами и пальцами;

- вырезание ножницами.

Все упражнения подбираются строго индивидуально и зависят от целей занятия. Также для развития сенсорных и моторных навыков употребляются ёмкости с песком, мукой и разными крупами. В дошкольной и школьной практике существует большое разнообразие игр: сбор песка, спящие пальцы, волны, следы [5, с. 31].

В процессе занятий используются такие методы, как:

- игры и упражнения, направленные на развитие социальных навыков (обучение алгоритму мытья рук по карточкам с картинками либо тренировка непосредственного мытья рук, либо тренировка в мини-группе, где происходит взаимодействие со сверстниками, обучение совместной игре и многим другим видам полезных и интересных навыков);

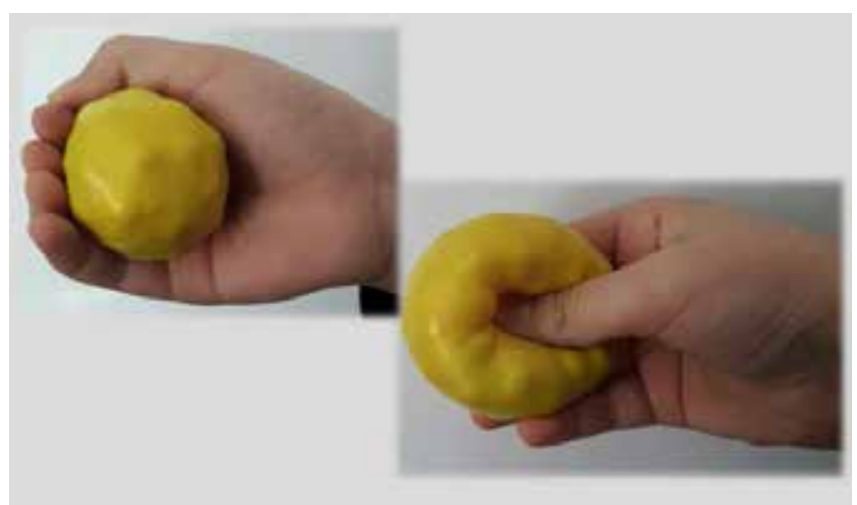

Рис. 3. Мячи разные по размеру и текстуре
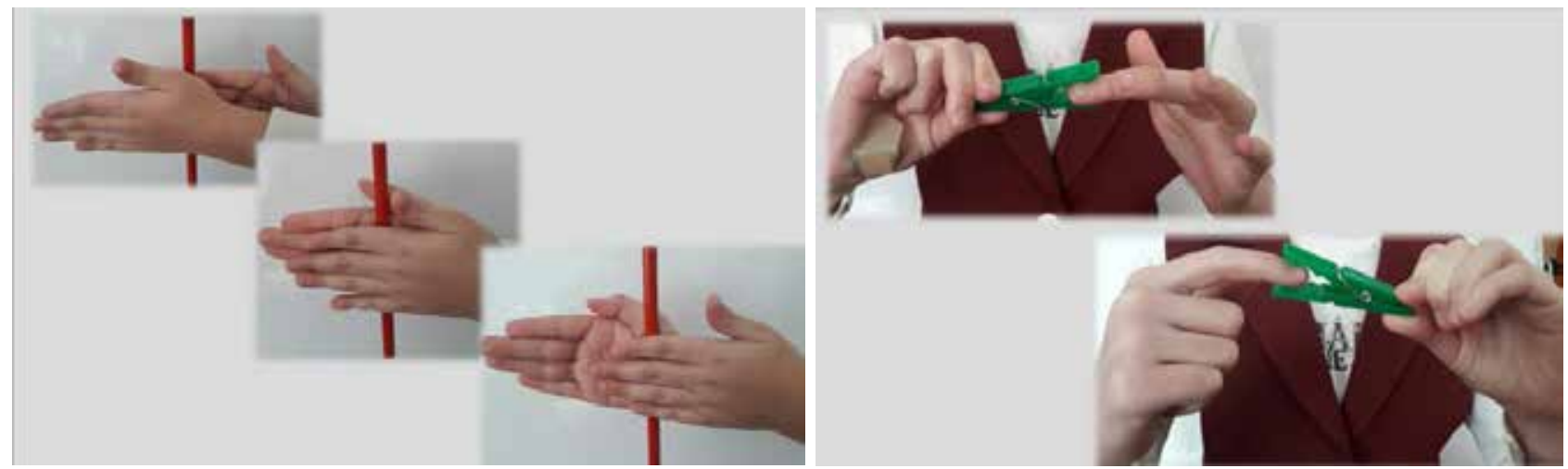

Рис. 4. Активация нервных окончаний 


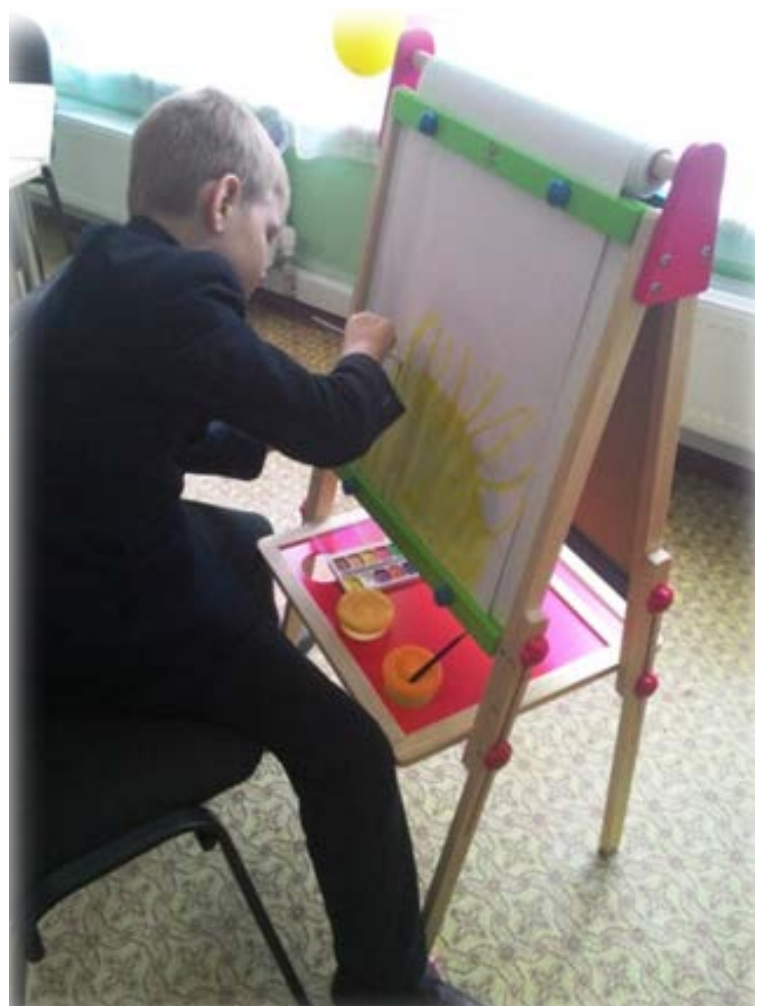

Рис. 5. Рисование кисточкой

- игры на развитие сенсорного восприятия, памяти, внимания;

- арт-терапия (рисование, лепка, оригами, квиллинг (в том числе из пластилина), поделки из природных материалов...).

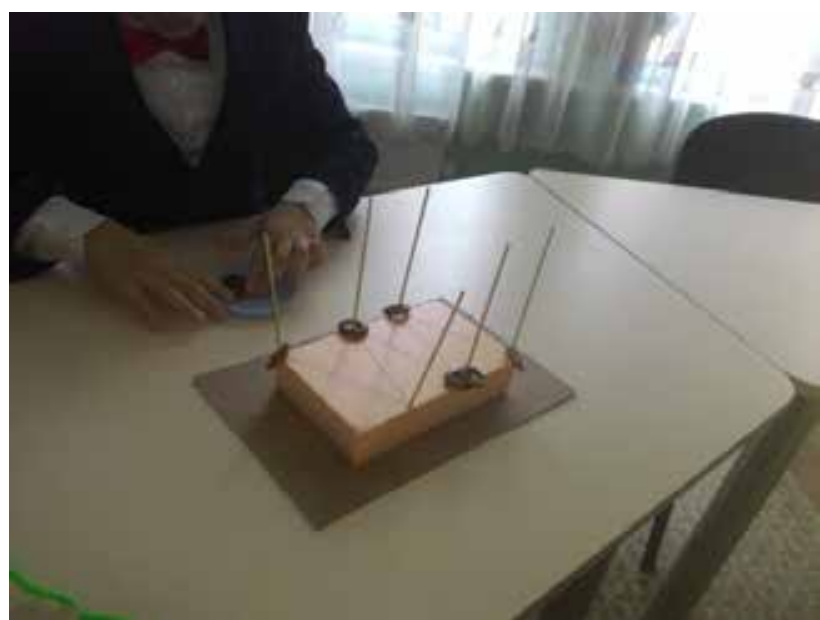

Рис. 6. Лабиринт

Активность в повседневной жизни включает в себя мероприятия по личной гигиене:

- уход за волосами;

- умывание;

- использование туалета;

- одевание;

- приём пищи.

К примеру, при обучении обуванию и шнурованию наиболее оптимальные положения для обувания следующие:

- сидя на стуле, ноги на полу, корпус наклонен вперёд;

- сидя на стуле, ноги на подставке, на высоте чуть ниже стула;
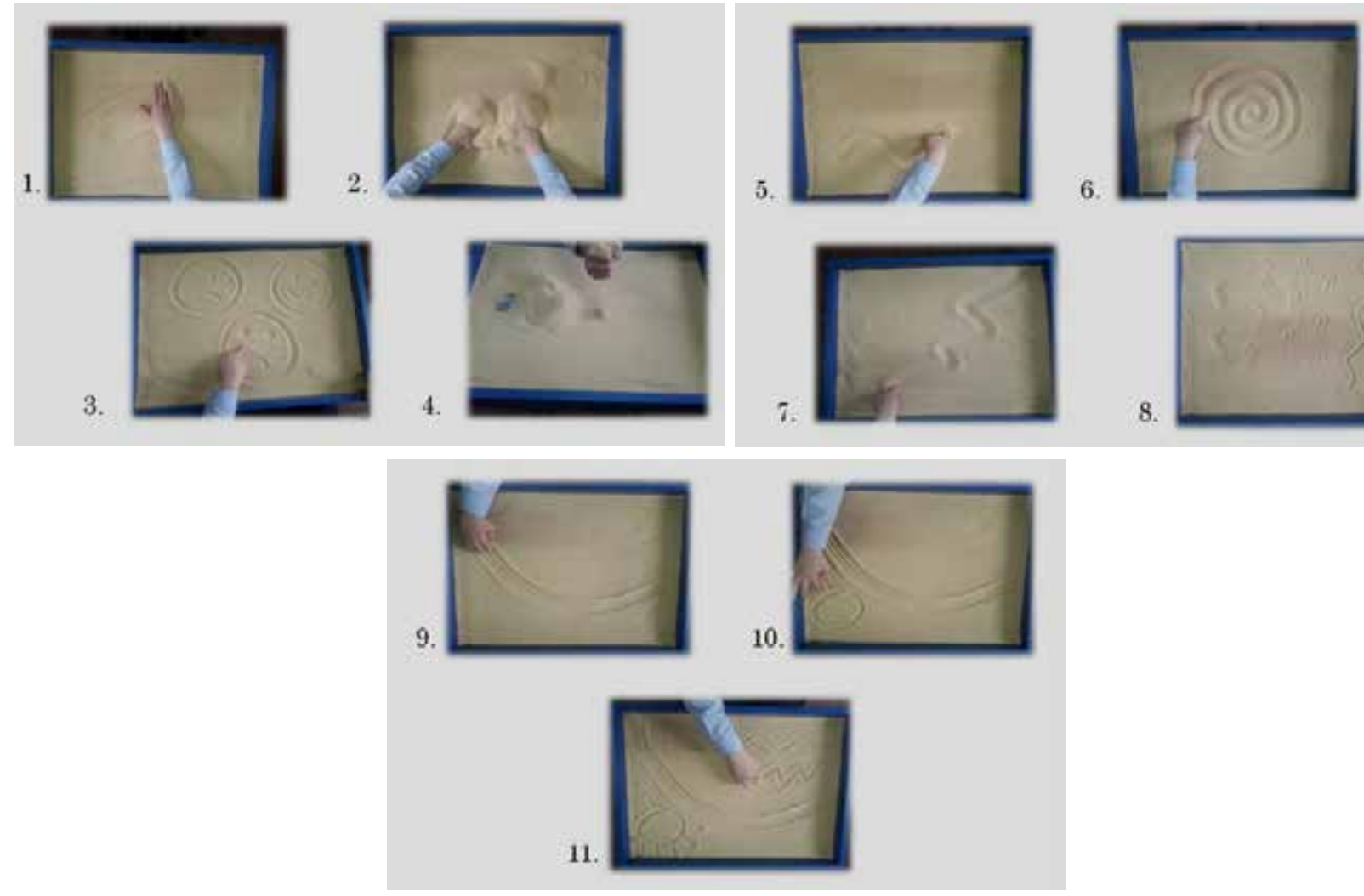

Рис. 7. Упражнения для развития сенсорных и моторных навыков 


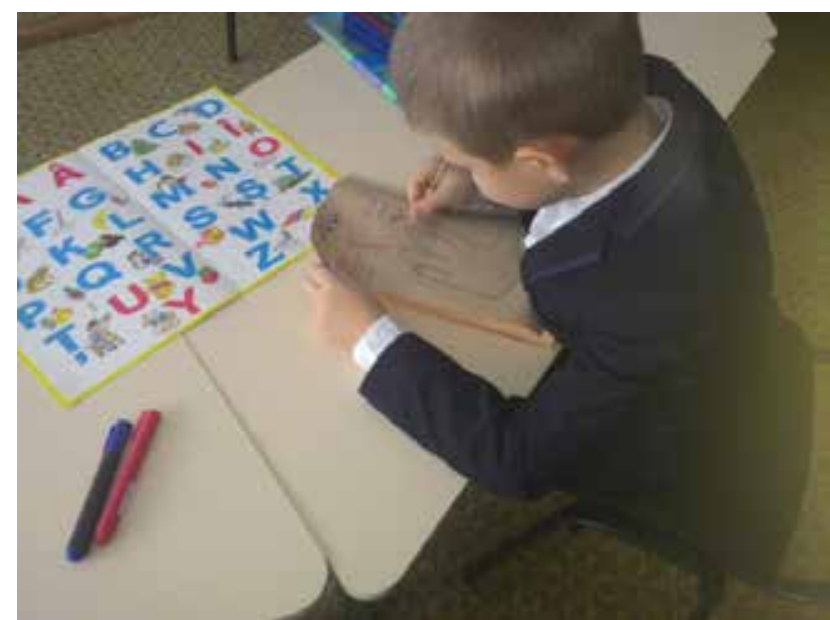

Рис. 8. Занятие на развитие внимания

- сидя на полу, колени согнуты.

При обучении шнурованию необходимо развивать захват большим и указательным пальцами. Если есть какие-либо проблемы, то сначала тренируются на деревянной обуви (макете), используя шнурки разного цвета, чтобы было легче запомнить механизм шнурования [3, с. 79]. Шнурки должны быть с толстым наконечником. Затем используются шнурки одного цвета. Ребёнок шнурует обувь, поставленную перед ним на столе пяткой к нему. В случае затруднений со шнуровкой необходимо повторять операцию каждый раз сначала. Для завязывания шнурка узлом необходимо научить ребёнка скрещивать шнурки, образуя круг, пропуская один конец шнурка внутрь этого круга.

Обучение застёгиванию пуговиц - долговременный и трудный процесс. Застёгивание требует хорошего захвата большим и указательным пальцами доминирующей руки. Сначала ребёнка учат вставлять пуговицы (продолговатые деревянные, картонные) в отверстия, затем - застёгивать и расстёгивать пуговицы, начиная с больших, при этом петли должны быть немного больше необходимого размера. Следующий этап - обучение ребёнка застёгиванию собственной одежды, положенной перед ним на столе, затем - застёгиванию одежды на себе.

Позитивное отношение к работе и энтузиазм во время занятий - это те качества, которые необходимы для успешной работы с ребёнком. Нужно, чтобы педагог улыбался ребёнку, подбадривал его и хвалил за работу во время занятий. Кроме того, педагог должен уметь гибко адаптировать упражнения и задания в соответствии с потребностями ребёнка [2, с. 165]. Чаще всего ребёнок приходит на занятия один-два раза в неделю, поэтому необходимо тесно сотрудничать с родителями, стараясь организовывать повседневную жизнь ребёнка так, чтобы развивать и закреплять результаты, достигнутые во время школьных занятий [1, с. 79; 4, с. 24].

Сегодняшний педагог должен лучше понимать теорию и практику своей деятельности, следовать определённым принципам, без которых немыслим образовательный процесс детей с особыми образовательными потребностями для их успешной интеграции в обществе. Для более эфрфективной помощи этим детям необходимо менять представления о потребностях людей с нарушением развития и учиться воспринимать таких людей в целостном контексте, учитывая их жизненные ценности и интересы.

Таким образом, главная цель занятий в школе это социальная адаптация, которая требует комплексного и индивидуального подхода к ребёнку. В таких ситуациях имеет значение все: окружение человека, образ его жизни, личные склонности и увлечения, уровень интеллекта. Всё это очень важно, поскольку задача педагога - улучшить качество жизни и дать ребёнку возможность не только самостоятельно обслужить себя, но и быть полезным обществу.

\section{БИБЛИОГРАФИЧЕСКИЙ СПИСОК:}

1. Bulat G. Suport educațional. Asistența copiilor $\mathrm{cu}$ cerințe educaționale speciale. Chișinău: Lumos Foundation, 2015. $150 \mathrm{p}$.

2. Colette de Bruin. Auti-comunicare. Give me 5. Nederlande: Graviant educatieve uitgaven, Doetinchem, traducere Inge J. Smelik, 2012. 176 p.

3. Degrieck S. Gândeşte şi aplică. Iaşi, România: Fides, 2010. 118 p.

4. Walsh K. Crearea claselor orientate după necesităţile copiilor de 8,9,10 ani. Chişinău: Pas cu Pas,1999. 231 p.

5. Zorilo L., Pereteatcu M., Rusov V., Panco T. Jocul cu nisip în educația incluzivă. Ghid pentru cadrele didactice și părinți. Bălți: Tipografia din Bălți, 2017. 52 p.

6. Косински К. Эрготерапия для детей с аутизмом: Эфрфективный подход для развития навыков самостоятельности у детей с аутизмом и РАС. Рама Паблишинг, 2017. 160 с. 